\title{
Razões para a queda do lulismo
}

Reasons for the decline of lula's political movement

Diego Pereira Siqueira ${ }^{1}$

\section{Resumo}

O presente artigo tem por objetivo contribuir com o debate sobre o significado do ciclo políticoeconômico "lulista" no Brasil e as razões de seu dramático declínio. Busca-se apontar algumas das causas do esgotamento de um modelo que se colocou como alternativa ao liberalismo, que caracterizou a década de 1990, também denominado de Neoliberalismo ou Consenso de Washington. Segundo nossa hipótese, uma das razões para o enfraquecimento da fórmula de conciliação de classes representada por Lula foi o fortalecimento de um padrão de reprodução capitalista exportador de especialização produtiva, encarnado pelo setor do agronegócio e pelo das atividades financeiras. Embora os grandes superávits comerciais proporcionados por esses setores tenham sido decisivos para os programas sociais que garantiram o sucesso político do lulismo, a partir da crise mundial de 2008, o agronegócio tornou-se o pivô de um realinhamento no bloco de poder, que se expressou no colapso do lulismo, com o impeachment de 2016.

Palavras-chave: Lulismo. Capitalismo dependente. Padrão de reprodução do capital.

\begin{abstract}
The following article aims to contribute to the debate about the meaning of president Luiz Inácio Lula da Silva's political and economic cycle and the reasons behind its dramatic decline. It seeks to point some of the causes for the exhaustion of a model that placed itself as an alternative to 90's liberalism, also known as Neoliberalism or the Washington Consensus. As per our hypothesis, one of the reasons for the weakening of the class-conciliatory formula represented by Lula was the growing strength of a capitalistic production standard based on exports and economic specialization, embodied by agrobusiness and the financial sector. Although the great commercial surplus enabled by these sectors were pivotal for the social programs that guaranteed the political success of Lula's movement, agrobusiness, starting with the 2008 financial crisis, played a key role in a power shift that culminated in the colapse of that movement with Dilma Roussef's impeachment in 2016.
\end{abstract}

Keywords: Lulism. Dependent capitalism. Capital reproduction pattern.

\section{Introdução}

Em menos de quatro anos, o lulismo passou de fórmula política que parecia consolidar o papel do Brasil como potência emergente do cenário internacional a principal bode expiatório dos nossos problemas econômicos, políticos e sociais. Nada simboliza esse fato com mais

\footnotetext{
${ }^{1}$ Mestre e doutor em Ciências pelo Programa em Integração da América Latina pela Universidade de São Paulo. E-mail: diegofolkmetal@gmail.com
} 
clareza do que o destino de seu principal protagonista, o ex-presidente Luiz Inácio Lula da Silva: de estadista mundial, passou a réu por corrupção, foi condenado em um processo relâmpago e atualmente está encarcerado, lutando para salvar sua biografia e seu legado.

Ao mesmo tempo, o Brasil sofre sua mais grave crise econômica em décadas, amargando um índice de desemprego de 12.492 milhões em outubro de $2018^{2}$, à qual se conjugam uma crise de segurança pública (26.126 mortes violentas no primeiro semestre de 2018) e uma crise sem precedentes da legitimidade das instituições, que, segundo alguns autores (como Maud Chirio), encerra o ciclo da Nova República, aberto com a redemocratização iniciada em $1985^{3}$. Esses fenômenos criaram as condições sociais para a eleição de um governo conservador, comprometido com as forças políticas mais retrógradas da sociedade brasileira.

Por que houve uma mudança tão abrupta? As razões para a queda do lulismo não estariam, como sementes, presentes nas condições que permitiram seu sucesso? São essas algumas das questões que tentamos responder neste artigo, que analisa o fenômeno lulista a partir das tendências estruturais do contexto econômico-social em que ele surgiu, ou seja, como um fenômeno político atuante em uma economia periférica, submetida às leis do capitalismo dependente e a um contexto histórico de ascensão das atividades exportadoras primárias, puxada pela ascensão da China como principal motor do capitalismo mundial. Assim, em nossa análise nos apoiaremos no instrumental teórico formulado pela Teoria Marxista da Dependência, em especial nos conceitos de superexploração do trabalho e de padrão de reprodução do capital. Comecemos por definir este e aplicá-lo, em linhas gerais, à análise da evolução da inserção internacional brasileira nas últimas duas décadas, nas quais o lulismo surgiu e atuou.

\section{O padrão de reprodução do capital}

Como expressado na introdução, utilizaremos aqui o conceito de padrão de reprodução do capital, definido como:

\footnotetext{
“A condensação de um conjunto de regularidades do movimento do capital no tempo histórico e em espaços geoterritoriais definidos, no contexto da economia e do sistema político-mundiais e como nível de abstração intermediário entre as formações sociais e o sistema mundial”. (FERREIRA; LUCE, 2012, p. 17).
}

\footnotetext{
2 Dados da Pesquisa Nacional por Amostra de Domicílios Contínua (PNAD Contínua) do IBGE, realizada em setembro de 2018.

3 Por exemplo, a historiadora francesa Maud Chirio, em entrevista à revista Fórum. Ver: https://www.revistaforum.com.br/para-historiadora-eleicao-de-bolsonaro-marca-fim-da-novarepublica/?fbclid=IwAR1Bzm3rIA5a9g-reqxQloDyz2MhoOQPjnlrrcOA5E3QRDpet8IoKasxqCg.
} 
Nas palavras do chileno Jaime Osório, que foi o primeiro a propor esse conceito:

\begin{abstract}
A noção de padrão de reprodução do capital surge para dar conta das formas como o capital se reproduz em períodos históricos específicos e em espaços geoterritoriais determinados, tanto no centro como na semiperiferia e na periferia, ou em regiões no interior de cada um deles, considerando as características de sua metamorfose na passagem pelas esferas da produção e da circulação (como dinheiro, meios de produção, força de trabalho, novas mercadorias, dinheiro incrementado), integrando o processo de valorização (incremento do valor e do dinheiro investido) e sua encarnação em valores de uso específico (calças, rádios, celulares, tanques de guerra), assim como as contradições que esses processos geram (OSÓRIO apud FERREIRA; LUCE, 2012, p. 40-41).
\end{abstract}

Ainda segundo Osório, a "produção capitalista tem sentido como busca incessante da valorização do capital. Nesse quadro, não pode ser assumida apenas como um processo de produção, mas sim, principalmente como um processo de reprodução.” (op. cit. p. 62-63, grifos nossos). Esse conceito define o ciclo do capital (produção, circulação e realização) e como ele se encarna em determinados valores de uso em cada momento histórico, como a atividade unificadora da reprodução societária e o ponto onde pode encontrar a racionalidade do processo político.

A América Latina, desde o processo de independência e o de consolidação de seus Estados Nacionais, apresentou de forma nítida dois padrões: o primário-exportador (de produtos agrícolas ou minerais), de meados do século 19 até mais ou menos a década de 1930, voltado para a satisfação das demandas do mercado externo, e o padrão industrial, que predomina dos anos 1940 aos 1970, quando as economias da região empreenderam esforços para construírem indústrias nativas, em atendimento às demandas do mercado interno.

Osório apresenta a proposta de que a América Latina, a partir dos anos 1990, desenvolve um novo padrão de reprodução. Abandonando o paradigma industrial, a região se insere na nova fase do capitalismo mundializado com um padrão exportador de especialização produtiva. Embora mantendo semelhanças com o antigo padrão exportador agromineiro do século 19, também apresenta diferenças substanciais: as atividades exportadoras, nessa nova organização, exibem elevado grau de inovação tecnológica, em muitos casos, concentrando os avanços em seu setor. Além disso, tais atividades constituem-se como segmentos de grandes cadeias produtivas globais, sob a direção de empresas transnacionais.

Apesar da presença do Estado em algumas atividades (mineração, petróleo/gás e energia elétrica), o setor dinâmico desse novo padrão de especialização produtiva encontra-se 
majoritariamente nas mãos do setor privado, onde o investimento estrangeiro e o capital financeiro ocupam papéis de destaque. Relevância cada vez maior, econômica e política, terá o setor do agronegócio. Assim, cria-se uma rede de interesses entre geradores de um fluxo de capital, como grandes fazendeiros, atores do mercado financeiro e multinacionais, cuja atuação não depende mais do mercado interno, mas do mercado mundial. Trata-se de um padrão que reatualiza as características da dependência em suas consequências mais perversas para a maioria da população, já que seu dinamismo e competitividade relacionam-se estreitamente à precarização das condições de vida e trabalho.

A ascensão desse novo padrão, por sua vez, está estreitamente ligada a mudanças drásticas na correlação de forças do sistema internacional, entre as quais, podemos destacar: I) o fim da União Soviética e a ofensiva estadunidense para retomar seu papel como potência hegemônica; II) a introdução de novas tecnologias de informação que aceleraram as comunicações e reduziram os preços do transporte de mercadorias; III) a ascensão de uma nova classe burguesa que tem como atividade principal as operações financeiras internacionais e que possui peso decisivo na definição das políticas nos organismos multilaterais, dando início ao processo que a maioria dos cientistas sociais chama de globalização e que Osório define como a mundialização do capital.

Nos países periféricos da América Latina, esse processo levou ao abandono, por parte das elites locais, de qualquer projeto de desenvolvimento capitalista autônomo e suas frações dirigentes passaram a apostar novamente em um projeto exportador trazido pelo novo padrão de reprodução capitalista. Mesmo que em alguns países ainda exista um setor industrial relevante (como no caso do Brasil), ele se encontra subordinado às parcelas do capital ligadas à exportação, cujos interesses moldam as políticas econômicas implementadas pelos Estados. Nessa nova conjuntura, os setores industriais que conseguem sobreviver são aqueles integrados "ao novo projeto exportador, no qual os eixos exportadores constituem, em geral, segmentos de grandes cadeias produtivas globais sob a direção de empresas transnacionais" (op. cit., p. 106). Nos anos 1990, essa mudança no padrão de reprodução ainda não era muito visível, mas, no início do novo século, com a mudança da composição da pauta exportadora da região ${ }^{4}$, ela se tornou evidente.

A abertura econômica e a internacionalização dos setores financeiro e produtivo acentuaram, nos anos 1990, os traços estruturais da economia dependente brasileira, em

\footnotetext{
${ }^{4}$ No Brasil, por exemplo, a conversão ao novo padrão primário-exportador começa a se dar de forma nítida apenas em 1998, após a crise cambial que pressionou pelo aumento das exportações para manter o equilíbrio das contas correntes. A esse respeito, ver Delgado (2012).
} 
especial, a tendência à precarização e deterioração das condições de vida e de trabalho da população assalariada, que viu sua participação na renda nacional diminuir no período de 1990 a 2002. Ainda segundo Osório, isso se deu por causa da própria natureza do novo padrão de reproduçãor, porque o salário médio local não consegue fornecer um mercado adequado para absorver a oferta dos produtos exportáveis, o que aponta para "uma estrutura produtiva dinâmica que se afasta e se desliga das necessidades da maioria da população" (op. cit., p. 123). Em segundo lugar, a própria vantagem competitiva desse padrão nos mercados internacionais reside justamente na deterioração dos salários e dos custos do trabalho, principal fator que atrai Investimentos Estrangeiros Direito (IED) para a região, seguindo a tendência internacional do capital de sair das regiões onde o custo da mão de obra é alto. Para os trabalhadores dos países dependentes, essa situação põe em questão até mesmo as conquistas limitadas oriundas da época do padrão industrial:

\begin{abstract}
A deterioração dos salários e das condições laborais em geral aponta, dessa forma, para o centro da dinâmica e da reprodução do novo padrão exportador. Assim como na segunda metade do século XIX e no início do XX, o grande capital que opera na região está mais preocupado com o nível de vida da população dos mercados para onde exporta e com o poder de consumo dos trabalhadores que lá se encontram do que com os da população assalariada local. Para esse capital, os trabalhadores locais interessam mais como produtores do que como consumidores. (FERREIRA; LUCE, 2012, p. 124).
\end{abstract}

Por sua vez, a tendência à perda do poder aquisitivo do trabalho na renda nacional ${ }^{5}$ implica outro fenômeno, também relacionado à tendência à desindustrialização: o aumento da população desempregada ou subempregada, que precisa encontrar formas de subsistência à margem das relações formais de trabalho. Esse setor da população trabalhadora (o subproletariado $^{6}$, na definição de André Singer), pela própria especificidade de sua posição na estrutura produtiva, encontra grandes dificuldades para uma organização coletiva do tipo sindical tradicional, o que por sua vez reforça sua vulnerabilidade frente à pressão do capital para a diminuição de seus rendimentos. Falaremos dele mais adiante mas, antes, vejamos as condições concretas em que se deu a adoção desse novo padrão no Brasil.

\footnotetext{
${ }^{5}$ Como toda tendência econômica, ela também pode se ver contrarrestada por contratendências que neutralizam ou atenuam seus efeitos por certo período. Por exemplo, no governo Lula, os indicadores econômicos mostram um relativo aumento do índice de Gini sobre distribuição de renda, apesar de, como veremos, não ter atenuado a tendência à superexploração do trabalho. Não obstante, em determinado momento a tendência volta a se reafirmar frente às contratendências opostas.

${ }^{6}$ Segundo André Singer, pertencem ao proletariado aqueles que "oferecem sua força de trabalho no mercado sem encontrar quem esteja disposta a adquiri-la por um preço que assegure sua reprodução em condições normais" (SINGER: 2012, p. 77). São empregados domésticos, trabalhadores sem carteira assinada e sazonais, autônomos e empregados de pequenas empresas, com renda per capita entre até um salário mínimo e dois salários per capita.
} 


\section{A crise cambial de 1998 e a ascensão do agronegócio}

Atualmente, o setor do chamado agronegócio ${ }^{7}$ é um dos mais importantes da economia brasileira, sob o ponto de vista da geração de superávits na balança comercial e do crescimento do PIB do país, sendo, por isso, essencial para o equilíbrio das contas públicas e para a capacidade de investimento do Estado. É através de suas atividades que o Brasil logrou se conectar ao novo centro dinâmico da economia mundial, a China, reformatando sua geoeconomia para atender à gigantesca demanda dessa nova potência por matérias primas e alimentos. Em vista disso, o agronegócio representa um dos setores mais poderosos e influentes politicamente dentro do atual bloco de poder no Estado brasileiro.

De acordo com alguns autores, como Delgado (2013), a crise cambial de 1998 foi decisiva para a reorganização da agricultura brasileira baseada no agronegócio, pois a elevação na taxa real de câmbio é favorável às exportações. A fim de suprir os déficits da conta corrente e se adequar às exigências impostas pelos três empréstimos concedidos pelo $\mathrm{FMI}^{8}$, o país passou a perseguir a estratégia de gerar saldos comerciais a qualquer custo, privilegiando o setor agrário-exportador na elaboração da política macroeconômica externa e da política agrícola interna.

O recurso à solução agroexportadora para combater o desequilíbrio externo foi mantido pelo lulismo, forjando um verdadeiro pacto para a acumulação de capital na agricultura, com base na reconstituição do crédito público bancário por meio do Sistema Nacional de Crédito Rural (SNCR), e na alta substancial do preço da terra e dos arrendamentos rurais. Quando a demanda por commodities puxada pela China aumentou, havia uma estrutura institucionalfinanceira capaz de aproveitá-la. Os dados da tabela 1 mostram a evolução constante do saldo comercial do agronegócio brasileiro. Em oito anos, as exportações mais que triplicaram e o saldo comercial aumentou em quatro vezes, conforme dados da tabela a seguir:

\footnotetext{
${ }^{7}$ Segundo Stédile (2013, p. 33), as características do modelo de produção do agronegócio contemporâneo, que o diferenciam do antigo latifúndio, são as seguintes: organização da produção agrícola na forma de monocultivo em áreas cada vez maiores; uso intensivo de máquinas agrícolas, também em escala cada vez mais ampla, expulsando a mão de obra do campo; uso intensivo de agrotóxicos, que contaminam a água dos lençóis freáticos e os alimentos; uso cada vez maior de sementes transgênicas e agressão ao meio ambiente com técnicas de produção que buscam apenas a maior taxa de lucro em menor tempo. Delgado (2013, p. 64) descreve o agronegócio como a "associação do grande capital agroindustrial com a grande propriedade fundiária". Isso deixa explícita a estreita associação entre a nova forma de exploração da terra com padrões industriais de competitividade e eficiência, como bem ressalta Moreno (2015): “O agronegócio brasileiro não se vê como um setor do 'extrativismo', mas como um complexo de cadeias de produção (...), que 'fabrica comida' ou 'proteína', linguagem que vem sendo incorporada também nos discursos oficiais do governo" (MORENO, 2015, p.55)..

${ }^{8} \mathrm{O}$ primeiro empréstimo, de $\$ 41,5$ bilhões, foi fechado por FHC em novembro de 1998. O segundo, de \$15,650 bilhões, foi acordado em setembro de 2001. O último foi negociado em agosto de 2002, pouco antes das vésperas das eleições. Todos eles foram pagos até o final do primeiro governo Lula.
} 
Tabela 1- Balança comercial do agronegócio brasileiro (US\$ bilhões)

\begin{tabular}{|c|c|c|c|}
\hline Período & Exportações & Importações & Saldo \\
\hline 2000 & US\$ 20.610 & US\$ 5.799 & US\$ 14.811 \\
\hline 2001 & US\$ 23.863 & US\$ 4.847 & US\$ 19.016 \\
\hline 2002 & US\$ 24.839 & US\$ 4.492 & US\$ 20.347 \\
\hline 2003 & US\$ 30.639 & US\$ 4.791 & US\$ 25.848 \\
\hline 2004 & US\$ 39.015 & US\$ 4.881 & US\$ 34.134 \\
\hline 2005 & US\$ 42.000 & US\$ 5.000 & US\$ 37.000 \\
\hline 2006 & US\$ 52.040 & US\$ 11.86 & US\$ 40.180 \\
\hline 2007 & US\$ 58.400 & US\$ 8.700 & US\$ 49.700 \\
\hline 2008 & US\$ 69.400 & US\$ 11.200 & US\$ 58.200 \\
\hline
\end{tabular}

Fonte: Mapa (Ministério da Agricultura, Pecuária e Abastecimento, 2009).

Um dos resultados desse avanço do agronegócio foi o rearranjo de setores das elites que se traduziu no

"pacto do agronegócio se espraiando pelo conjunto da economia, e impondo cada vez mais uma estratégia privada e estatal de perseguição da renda fundiária como diretriz principal de acumulação de capital ao conjunto da economia" (DELGADO, 2012, p. 111).

A essa estratégia, coincidiu um momento particular das relações internacionais em que o Estado brasileiro foi obrigado a se posicionar contrariamente às propostas de livre comércio defendidas pela potência norte-americana, que prejudicariam sua indústria sem abrir perspectivas promissoras de acesso ao mercado dos EUA para nossas exportações primárias. Tal circunstância facilitou a aproximação dos setores industrial e do agronegócio à proposta de política externa defendida pelo lulismo de inserção "sul-sul” e de diversificação de parceiros comerciais, facilitando assim a realização do pacto político de conciliação ${ }^{9}$. Assim, embora o lulismo ainda apontasse para um horizonte industrializante, ele passaria a depender de forma decisiva dos superávits comerciais proporcionados por esse setor para o sucesso de sua fórmula de conciliação, o que cobraria seu preço futuramente.

\section{O lulismo}

A já extensa bibliografia sobre o lulismo tem como denominador comum sua caracterização como um governo de conciliação de classes, que, ao mesmo tempo em que

\footnotetext{
${ }^{9}$ Essa aproximação de setores da burguesia brasileira ao lulismo, determinada pela frustração com as negociações de livre comércio com os EUA, é discutida por Berringer (2015).
} 
mantinha as diretrizes macroeconômicas conservadoras do governo anterior (juros altos, combate à inflação etc.) realiza as aspirações de consumo e integração social (via programas sociais e política de valorização do salário mínimo) de uma parcela significativa da população trabalhadora mal paga, o subproletariado, que passa a atuar como a principal base social de seu governo. Também, a maioria das análises concorda que o lulismo só adquire sua feição definitiva com as eleições de 2006, quando conquista o apoio desse segmento.

Segundo André Singer (2012), uma das principais características políticas do subproletariado enquanto fração de classe é seu conservadorismo, que o torna avesso à mobilização coletiva e receptivo às propostas de melhoria de suas condições de vida que não perturbem a estabilidade política. Sua interpretação é que o lulismo

\begin{abstract}
... é, sobretudo, representação de uma fração de classe que, embora majoritária, não consegue construir desde baixo as próprias formas de organização. Por isso, só pode aparecer na política depois da chegada de Lula ao poder. A combinação de elementos que empolga o subproletariado é a expectativa de um Estado suficientemente forte para diminuir a desigualdade sem ameaças à ordem estabelecida (SINGER, 2012, p. 52 , grifo do autor).
\end{abstract}

Ao deslocar sua base social fundamental do sindicalismo classista para esse setor, o petismo se metamorfoseia em lulismo, já que Lula passa a ser o mediador entre os interesses do subproletariado e de setores da burguesia interna brasileira, equilibrando-se entre eles e gerenciando o sistema político em função de um projeto de conciliação de classes fundada num pacto conservador. E aqui, vemos uma diferença crucial do lulismo em relação ao populismo de Getúlio Vargas, ao qual foi frequentemente comparado: este se construiu como porta-voz dos interesses industrialistas de setores do empresariado e da classe operária urbana, impulsionando um projeto de modernização econômica que, sem romper de forma decisiva com o setor agrário, representou uma alteração na correlação de forças internas. Se aceitarmos o lulismo como representante dos interesses de uma fração de classe que não possui um projeto próprio de sociedade (seu interesse seria desaparecer, como bem coloca o próprio Singer ${ }^{10}$ ), o projeto social assumido por ele teria sucesso apenas enquanto existissem as condições propícias à sua prática de conciliação e equilíbrio, e que desapareceria assim que a correlação de forças

\footnotetext{
10 "O ponto central a ser levado em conta é que o subproletariado tende a desaparecer conforme o programa que ele apoia se converte em realidade. Como o projeto do subproletariado é sumir, ele não possui um modelo próprio de sociedade, desejando (inconscientemente) incorporar-se àquela que é moldada pelos interesses de outras camadas. Isso o coloca em posição de neutralidade e, portanto, favorece a arbitragem com respeito a questões como a diminuição da desigualdade (não confundir com a redução da pobreza) por meio da construção do Estado de bem estar e a desindustrialização do país. Cumpre insistir que o seu projeto é o da diminuição da pobreza, não necessariamente da desigualdade, que são coisas distintas, embora relacionadas" (SINGER: 2012, p. 156).
} 
se alterasse a favor de alguma das classes fundamentais da sociedade, por exemplo, a burguesia agroexportadora.

No que tange a setores da burguesia industrial, o lulismo significou uma retomada do papel econômico do Estado, não mais como produtor, mas como orientador e investidor, permitindo a um grupo seleto de empresas (as gigantes nacionais) expandirem e internacionalizarem seu raio de operações e competirem no mercado internacional em condições vantajosas. Por meio de empréstimos e da abertura de linhas de crédito, o Banco Nacional de Desenvolvimento Econômico Social (BNDES), capitalizado com recursos oriundos de fundos de pensão e do Fundo de Amparo ao Trabalhador, tornou-se o principal instrumento da política externa brasileira e o principal ator econômico por trás da emergência das multinacionais brasileiras ${ }^{11}$. Portanto, o lulismo representou também uma reorganização de setores da burguesia brasileira identificados com os interesses industriais, que abarcam o que Berringer (2015) chama de burguesia interna ${ }^{12}$. Segundo suas palavras, com o lulismo "o Estado tratou de construir uma imagem que refletisse e ao mesmo tempo expandisse a capacidade econômica da grande burguesia interna". (BERRINGER, 2015, p. 188). Esse setor da burguesia abarca as grandes empresas de capital predominantemente nacional, algumas estatais e, ocasionalmente, algumas multinacionais aqui instaladas (op. cit., p. 150). Concentradas na área de energia e recursos naturais (Petrobrás e Vale), infraestrutura e logística (Odebrecht, OAS, Camargo Corrêa, Andrade Gutierrez, Queiroz Galvão) e alimentos (JBS, Friboi e Sadia), essas grandes empresas receberam vultosos financiamentos do BNDES para fusões e aquisições e a construção de grandes obras de engenharia que interessavam, de forma direta ou indireta, também a outros interesses econômicos do Estado brasileiro.

Entre os vários objetivos perseguidos pela política econômica lulista, podemos listar a reversão do processo de desnacionalização total de setores estratégicos, a garantia de controle

\footnotetext{
${ }^{11}$ Uma referência detalhada do papel do BNDES nesse período está em LUCE (2007). Embora a pesquisa analise apenas o primeiro mandato de Lula, quando suas políticas caracterizavam-se mais pelo continuísmo da ortodoxia monetária, segundo Singer (2012) e Ricci (2013), ele confirma que a política externa de Lula se pautava por uma atitude mais pró-ativa, o que denota um amplo consenso sobre sua estratégia sul-americana entre o bloco de forças sociais que lhe davam sustentação.

${ }^{12}$ A autora, seguindo Poulantzas, faz uma distinção entre burguesia propriamente nacional e a burguesia interna. A primeira possui uma base de acumulação própria no interior de uma formação nacional e, portanto, pode apresentar certa autonomia política e ideológica frente ao capital estrangeiro. A burguesia interna ocupa uma posição intermediária entre a burguesia compradora e a burguesia nacional: "Essa fração mantém relações complexas com o capital imperialista, pois possui base de acumulação própria e, ao mesmo tempo, é dependente do capital externo. Por isso, em certa medida, tenta limitar a presença do capital estrangeiro no mercado interno, a fim de garantir sua sobrevivência, mas não pretende romper os laços com o capital imperialista. Ela apresenta uma dissolução da autonomia política e ideológica, que faz com que não apresente interesse em construir uma aliança com as classes dominadas, ou seja, a burguesia interna não tem pretensões de tornar-se nacional" (BERRRINGER. 2015, p. 69).
} 
nacional de setores que ajudam na pauta exportadora (alimentos, papel e celulose, açúcar e álcool), a manutenção ou ampliação das exportações e criar condições para a remessa de lucros e a redução do déficit na balança de pagamentos (BERRINGER, 2015, p. 197). Uma prova de que isso foi uma opção política consciente, encontra-se na entrevista de Márcio Pochman, exdiretor do IPEA, à revista do Instituto Humanitas Unisinos, em 2010:

O que estamos observando nessas duas últimas décadas de predomínio da globalização, sobretudo financeira, e de desregulamentação do próprio Estado, é a constituição de grandes corporações transnacionais. Falava-se, antes da crise de 2008, da emergência de pelo menos 500 grandes corporações transnacionais, que dominariam todos os setores da atividade econômica. Nesse circuito de hipermonopolização do capital, os países que não tiverem grandes grupos econômicos e não forem capazes de fazer parte desses 500 grupos, de certa maneira, estarão de fora, alijados da competição de tal forma que passariam a ter um papel passivo e subordinado ao circuito de decisões desses 500 grupos. Então, a opção brasileira é se aproximar da concentração desses gigantes para, de certa maneira, fazer parte desse circuito de poucas, mas grandes empresas ${ }^{13}$

A confluência de interesses entre subproletariado, burocracia sindical, agronegócio e grande burguesia industrial gerou as condições necessárias para que o lulismo, tendo abandonado a perspectiva socialista de seus primórdios, se tornasse a representação política de uma frente neodesenvolvimentista. Conforme destacou Berringer:

\begin{abstract}
O neodesenvolvimentismo, como expressão dos interesses de um setor da burguesia interna, diferencia-se da antiga ideologia desenvolvimentista dos anos 1930 a 1980 pelas seguintes características: 1) índices mais modestos de crescimento; 2) menor ênfase ao protecionismo do mercado interno; 3) menor peso à indústria local; 4) aceitação da especialização regressiva, já que a produção se concentra em segmentos de baixa densidade tecnológica; 5) menor distribuição de renda; 6) maior fragilidade político-ideológica da fração burguesa; 7) busca por acesso a mercados para exportação de produtos primários e manufaturados; 8) a busca pelo aumento do IED brasileiro tornou-se uma estratégia de inserção internacional das empresas brasileiras impulsionadas pelo Estado através do BNDES e da política externa Sul-Sul; 9) não defesa do monopólio estatal da produção de petróleo, mas a adoção do modelo de partilha; 10) as obras de infraestrutura não são prioritariamente estatais, pois contam com parcerias público-privadas. (BERRINGER, 2015, p. 155).
\end{abstract}

\title{
Contradições do capitalismo dependente
}

O neodesenvolvimentismo constituiu-se então na ideologia unificadora das diversas frações de classe em torno do projeto lulista, resgatando algumas das velhas bandeiras de desenvolvimento e superação da pobreza dos anos 1950 e 1960. O clima de euforia e otimismo que marcou o fim do segundo mandato de Lula, com o Brasil apresentando-se como uma

13 "Estado brasileiro é ativo e criativo", entrevista de Marcio Pochman a Patricia Fachin, Revista IHU, n. 322, São Leopoldo, Universidade do Vale do Rio dos Sinos, 22 de março de 2010, p. 16. 
potência emergente, é indicativo do seu sucesso em cimentar a coesão entre esses segmentos. Entretanto, o capitalismo brasileiro ainda enfrentava dois obstáculos sistêmicos, que o impossibilitavam de deixar a condição dependente: "a deficiente capacidade de gerar inovações e a fragilidade de mecanismos de financiamento de longo prazo" (SARTI; LAPLANE, 2003, p. 52-53). As empresas brasileiras que adotaram a internacionalização são as que ocupavam nichos específicos de setores commoditizados e de serviços ou de baixa intensidade tecnológica, o que lhes permitia competir com empresas estrangeiras. No entanto, o padrão de divisão internacional norte-sul (com os países centrais detendo o virtual monopólio dos investimentos em P\&D) continuou prevalecendo, com o Brasil pouco investindo em áreas como robótica, biotecnologia ou tecnologia de informação. Portanto, o lulismo, pese sua política industrialista, pouco fez para superar uma das principais fragilidades sistêmicas da economia brasileira, dependente como está das vantagens comparativas em recursos naturais.

A esse respeito, Delgado aponta:

\begin{abstract}
Se atentarmos para a estrutura econômica dos setores que já crescem à frente dos demais, há alguns anos, veremos que existe certo denominador comum da produção do petróleo, da hidroeletricidade, do agronegócio e também da mineração. Todos esses ramos produtivos operam com base em monopólio de recursos naturais, que nas suas dotações originais independem de investimentos ou da aplicação do trabalho humano para produzi-las. Esses recursos, submetidos à exploração intensiva ou extensiva, derivada da demanda por commodities, produzem rendas fundiárias, que são objeto de ávida disputa no processo de apropriação da renda e da riqueza social. Dada a atual configuração da inserção do Brasil no comércio mundial, os recursos naturais passaram a figurar como vetor principal de competitividade externa. Os pressupostos dessa competitividade, baseada em estoques finitos de recursos naturais, é preocupante por várias razões. As matérias-primas aí produzidas apresentam baixa agregação de trabalho humano; há forte pressão por superexploração dos recursos naturais em curto prazo; e a inovação técnica de ponta do sistema industrial fica relativamente relegada a segundo plano (...), porque os ganhos em produtividade do subsistema exportador estão muito mais ligados às chamadas vantagens comparativas (DELGADO, 2012, p. 127-128).
\end{abstract}

Quanto ao segundo constrangimento sistêmico, há duas considerações a se fazer. A primeira é que o Brasil continua dependendo fortemente de Investimentos Estrangeiros Diretos (IED) para sua formação de capital fixo. Hiratuka \& Sarti (2011) nos oferecem o seguinte quadro da concentração de IEDs no período lulista: Ao contrário dos anos 1990, quando o IED se concentrou no setor de serviços, por conta das operações de fusões e aquisições de empresas privatizadas $(63,2 \%$ do total, contra $33 \%$ para a indústria), entre 2006 e 2008 cerca de $20 \%$ do total de IEDs para o Brasil tiveram por destino os setores agrícola e extrativo, o que corresponde ao início do boom das commodities puxado pelo crescimento chinês. A indústria como um todo obteve ligeira melhoria, de cerca de $35 \%$; no entanto, se observarmos sua composição, veremos 
um "aumento da participação relativa dos setores mais intensivos em recursos naturais, como alimentos, metalurgia e papel e celulose, em detrimento de setores como químico e automotivo" (op. cit., p. 17).

O setor de construção aumentou sua participação para 3,8\%, o que, a nosso ver, corresponde ao ciclo de grandes obras puxadas pelo Programa de Aceleração do Crescimento (PAC) e financiadas pelo BNDES. O setor de bens de capital, máquinas e equipamentos caiu de 5,6\% em 1995 para 1,4\% em 2006-2008, o que parece indicar a pouca contribuição que os IEDs representam para a formação de novas indústrias tecnologicamente mais avançadas.

A segunda consideração refere-se à elevada porcentagem da dívida pública em relação ao PIB. Uma das consequências dos massivos investimentos estatais do segundo mandato de Lula foi o aumento exponencial da dívida, que passou de $\mathrm{R} \$ 823$ bilhões em 2002 para $\mathrm{R} \$ 1,69$ trilhão em $2010^{14}$, puxado em sua maioria pelos empréstimos do Tesouro ao BNDES. Em um contexto de crescimento econômico, tal endividamento em si não é um problema, pois é compensado pelo ingresso de divisas derivadas das exportações e do crescimento econômico. Entretanto, em períodos de retração, a capacidade de financiamento estatal diminui de maneira dramática, constrangido pela necessidade de garantir a manutenção dos pagamentos dos serviços da dívida, o que gera, segundo especialistas em finanças públicas, a necessidade de obtenção de superávits primários. Com isso, há uma disputa entre diversos seguimentos burgueses para se apropriar do orçamento estatal.

Por sua força e posição dominantes, e também por suas conexões internacionais, a parcela do mercado financeiro da burguesia esteve em melhores condições de vencer essa disputa, por meio de políticas econômicas de manutenção de altas taxas de juros, da qual a economia dependente brasileira necessita para continuar a atrair investimentos estrangeiros diretos. Essa estrutura macroeconômica mostra a vigência dos mecanismos de dependência de transferência de renda dos países periféricos para os centrais. A inserção subordinada do Brasil na nova configuração do capitalismo internacional apontava para o fortalecimento do padrão de reprodução exportador de especialização produtiva e dos seus principais agentes, nomeadamente, os segmentos financeiro e agroindustrial da burguesia interna.

O lulismo não rompeu e não poderia romper com as tendências estruturais da economia brasileira, posto que sua proposta contemplava a conciliação sem rupturas no plano interno e, no plano externo, representa a concretização da tendência do Brasil se tornar "o nexo

\footnotetext{
${ }^{14}$ FERNANDES, Adriana; FROUFE, Célia. Dívida pública cresceu 105\% com Lula. Estadão.02 fev. 2011. Economia \& Negócios. Disponível em: https://economia.estadao.com.br/noticias/geral,divida-publica-cresceu105-com-lula-imp-,674086. Acesso em: 20 nov. 2018.
} 
intermediário da região [sul-americana] com o mercado mundial” (ZIBECHI, 2012, p. 204), ao alinhar os setores competitivos da economia com as oportunidades de crescimento e exportação ditadas pelas particularidades daquele momento específico do capitalismo. Dessa forma, o crescimento econômico e o relativo bem estar experimentados pelos setores populares na última década não significaram uma ruptura com a condição de dependência; mas, sua reedição sob novo patamar, respondendo mais uma vez às demandas e estímulos dos centros dinâmicos do sistema mundial, que se encontravam ocultas sob o aparente clima de prosperidade e consumo das classes populares.

Esse traço estrutural do capitalismo dependente, num momento de afirmação do padrão de reprodução agroexportador, significa que ele só pode manter suas taxas de lucro, mesmo em período de crescimento, graças à exploração intensiva dos recursos naturais e da força de trabalho, o que reafirma a tendência à superexploração do trabalho ${ }^{15}$ e o consequente fortalecimento do agronegócio no bloco de poder estatal. Para ilustrar esse ponto, vejamos alguns breves exemplos que confirmam nossa hipótese no campo ambiental e trabalhista e que revelam algumas das contradições da fórmula política lulista.

Apesar de ter contado, desde sua fundação, com a adesão de movimentos ecológicos e indígenas, o Partido dos Trabalhadores (PT) nunca priorizou a pauta ambiental. Seu núcleo duro vinha do sindicalismo operário do grande $\mathrm{ABC}$ paulista, predisposto à negociação de vantagens imediatas e visíveis para seus associados. Essa origem levou seus dirigentes a priorizarem a geração de empregos formais, relegando outras pautas. No poder, a conciliação de classes forjada pelo lulismo e soldada na ideologia neodesenvolvimentista desconsiderou a pauta ambiental, sacrificada perante a necessidade de geração de superávits e de condições de estabilidade. Por exemplo, em 2003, o governo Lula e seus representantes no Congresso Nacional posicionaram-se a favor da liberação do cultivo e comercialização das safras de soja transgênica na agricultura brasileira, contrariando movimentos sociais e até mesmo o parecer

\footnotetext{
15 A superexploração, como categoria econômica, não implica apenas um aumento da exploração via mais valia absoluta ou relativa, e sim que o valor da força de trabalho é violado de forma recorrente, seja por meio da apropriação, pelo capital, do seu valor diário, seja do seu valor total, este último entendido como o tempo total de vida útil do trabalhador. Como todas as categorias marxistas, os conceitos de valor diário e valor total são relacionais e históricos, dependendo das condições existentes em cada época. Por exemplo, se o tempo médio de vida útil de um trabalhador, em condições normais, for de trinta anos, seu pagamento diário deveria permitir que ele se mantenha de tal forma que possa se apresentar no mercado de trabalho por esse período. Entretanto, se o ritmo e a intensidade da jornada de trabalho impostos a ele forem tais que, ao longo de certo período, lhe causem um desgaste que encurte sua vida útil, pode-se dizer que o capital está lhe subtraindo hoje os anos futuros de trabalho e de vida. Isso implica que pode haver superexploração, mesmo quando há uma elevação do valor nominal dos salários, em situações em que aumenta o desgaste da força de trabalho sem que o trabalhador possa repor esse desgaste. Para mais informações, ver LUCE (2018).
} 
de órgãos como o IBAMA e a Anvisa. Esse fato foi importante porque marcou a aproximação de Lula com o PMDB e outros pequenos partidos da bancada ruralista, com o objetivo de compor uma base aliada para aprovar medidas de interesse do governo, e que depois evoluiu para a sólida aliança que se tornou um dos pilares do lulismo (LISBOA: 2010).

A grande demanda de alimentos causada pelo crescimento chinês ofereceu ao agronegócio condições sem precedentes para sua expansão comercial e territorial, avançando sobre áreas de preservação ambiental, quilombolas e indígenas. No campo político, isso se refletiu nos sistemáticos ataques da bancada ruralista à legislação ambiental, aos seus órgãos de fiscalização, às políticas de combate ao trabalho escravo e à concessão de mais terras para os povos originários. Para isso, essa bancada vem construindo alianças com outros grupos com visões retrogradas sobre direitos sociais, como evangélicos e militares (o que não significa dizer que esses três grupos tenham posições homogêneas ou que suas confluências não sejam isentas de contradições), construindo um discurso legitimador de que representa o setor "moderno" da economia. Uma consequência dramática desse fortalecimento do setor agroexportador dentro do bloco de poder se traduziu na extrema violência contra as populações vulneráveis, visível no elevado número de mortes de ambientalistas e lideranças de trabalhadores rurais em conflitos pela posse de terra. Segundo relatório divulgado pela ONG britânica Global Witness ${ }^{16}$, o país se coloca entre aqueles onde mais ocorrem assassinatos de ativistas ambientais: 29 homicídios registrados em 2014, à frente da Colômbia (25), Filipinas (15) e Honduras (12).

Além da violência pura e simples, o desenvolvimento desse padrão de reprodução capitalista acarreta consequências negativas na saúde e na capacidade laborativa dos trabalhadores rurais. Diversos estudos apontam para o aumento exponencial dos pedidos de auxílios por doença ou acidente de trabalho e de aposentadorias por invalidez dos trabalhadores rurais entre 2000 e 2009 (DELGADO, 2012, p. 122). Embora, no mesmo período, tenha havido um aumento percentual da massa de trabalhadores incluídos no sistema de previdência, é inegável o quadro dramático na situação dos segurados rurais, pois o número global de pessoas ocupadas no setor agrícola caiu, além de ser preciso considerar o fato de que o segurado rural encontra maiores dificuldades burocráticas para ter acesso às perícias médias do INSS. O grande responsável por esse aumento quase epidêmico do número de pedidos de auxíliosdoença tem sido o setor sucroalcooleiro, e não foi o corte de cana, a parte mais visível e dura do setor, o maior responsável pelos índices no aumento de pedidos de auxílio-doença: "Nas atividades de fabricação do açúcar e do álcool, a expansão do auxílio-doença é mais do que o

16 Disponível em: http://exame.abril.com.br/brasil/brasil-lidera-ranking-de-assassinato-de-ambientalistas/. Consultado em 18 out. 2018. 
dobro, relativamente à atividade agrícola" (DELGADO, 2012, p. 127). Essas são atividades tipicamente industriais, a face mais moderna da nova agricultura brasileira.

Assim, o avanço da formalidade das relações de trabalho, obtido no período lulista, apenas colocou em evidência o alto grau de exploração contido na colheita de cana de açúcar e suas atividades correlatas. Trata-se de um setor (o agronegócio) e de uma de suas partes constituintes (sucroalcooleiro) que têm se destacado nos últimos anos exatamente pelo grau de "modernização" e pelo alto investimento de capital em maquinarias e inovações tecnológicas, além de contar com o apoio decisivo do Estado em sua necessidade de gerar um volume maior de exportações e de apoiar o crescimento de setores competitivos da economia.

Temos diante de nós o exemplo dialético no qual o setor moderno da economia utilizase de formas arcaicas e intensivas de exploração do trabalho para aumentar a extração de mais valia e aumentar sua taxa de lucro, subtraindo ao trabalhador a possibilidade de obter condições estáveis para a manutenção e reprodução de sua força de trabalho, o que configura a vigência da categoria superexploração do trabalho na agricultura durante o período lulista. Quando o quadro econômico não foi mais favorável ao pacto de conciliação e à distribuição de benefícios para todas as classes, o agronegócio se somou à frente anti-lulista, que resultou no processo do impeachment de Dilma Rousseff, apoiando medidas de austeridade e as reformas trabalhista e previdenciária.

\section{Conclusão}

O período lulista sem dúvida representou um período de relativa melhoria no padrão de vida e no consumo das classes populares, aliada a uma projeção inédita de empresas de capital brasileiro para outras economias. Essa situação despertou tanto expectativas quanto temores de que o Brasil poderia, em um breve período, tornar-se uma potência emergente no cenário mundial, e diversos estudos e artigos debateram as consequências dessa hipótese ${ }^{17}$ para a economia e movimentos populares da América Latina.

Entretanto, indo além das análises superficiais, havia sérios constrangimentos sistêmicos que poderiam frustrar essa expectativa e que o lulismo não enfrentou diretamente. Entre elas, o pouco investimento em Pesquisa e Desenvolvimento, capaz de gerar inovações tecnológicas, e a deficiente estrutura de mecanismos de financiamento em longo prazo. Por sua vez, o novo padrão de reprodução capitalista que se firmou no Brasil apoia-se fortemente na

\footnotetext{
${ }^{17}$ Um excelente livro que exemplifica essa preocupação, do ponto de vista dos movimentos sociais, é o de Raul Zibechi, Brasil potência (2012).
} 
exploração intensiva de recursos naturais e do trabalho, relegando à indústria um papel secundário e condenando os direitos sociais como obstáculos ao seu processo de acumulação.

O pacto lulista de conciliação dependia diretamente das receitas advindas das exportações brasileiras, em um período marcado pela ascensão da China ao posto de maior economia mundial. Graças a isso, o lulismo pôde pôr em prática sua política de valorização do salário mínimo e programas sociais, que teve o efeito de aquecer o mercado interno e também de expandir um grupo seleto de grandes empresas, representantes de segmentos empresariais afinados com o projeto governamental neodesenvolvimentista. $\mathrm{O}$ crescimento do período, entretanto, deixou expostas as contradições de uma economia capitalista dependente, como a elevada superexploração do trabalho mesmo em setores que alcançaram uma excepcional expansão, caso do agronegócio e construção civil.

O esquema de conciliação de classes encontrava-se assentado sobre bases muito frágeis. Quando as receitas oriundas do setor exportador diminuíram, houve uma pressão das classes dirigentes para o Estado diminuir seus gastos, o que afetou diretamente os programas sociais que constituíram o esteio do apoio do subproletariado ao governo. Frente ao agravamento da crise iniciada em 2008, com a diminuição da renda das exportações de commodities, frações da grande burguesia industrial e financeira passaram a exigir cortes radicais, inclusive de direitos consolidados das classes trabalhadoras para seu fundo de manutenção (caso das reformas trabalhista e previdenciária), o que a nosso ver reitera a vigência da superexploração como categoria explicativa do capitalismo periférico dependente. Mesmo setores do empresariado nacional, que supostamente se veriam representados pela política neodesenvolvimentista do governo, alinharam-se à campanha contra o "intervencionismo estatal", para o que Singer sugeriu como razão a imbricação entre o capital da indústria e das finanças. Em outras palavras, "o controle das atividades produtivas por grandes grupos financeiros dilui seus antagonismos, fazendo com que os empresários se tornem mais receptivos à liderança ideológica do setor rentista" (SINGER, 2018, p. 66-67).

A luta entre as diversas correntes burguesas levou ao desmoronamento do pacto lulista, e pudemos ver até mesmo alguns grandes empresários, representantes da burguesia interna, sendo criminalizados por denúncias de corrupção e perdendo espaço na condução da política econômica. O impeachment de Dilma Rousseff e a prisão de Lula foram sinais claros que grandes setores do empresariado, do agronegócio e do setor financeiro, aliados à classe política tradicional e o judiciário, abandonaram de vez o projeto de conciliação lulista. Sem um dos polos do pacto, e sem mobilizar sua base social no subproletariado (algo que não conseguiria fazer, já que um dos seus aspectos era a despolitização e inclusão desse setor apenas pela via 
do consumo), o lulismo pairou no ar, cedendo pouco a pouco todas as suas posições. O escândalo de corrupção instrumentalizado pela Operação Lava Jato e as mobilizações de massa de setores da classe média forneceram o contexto político que legitimou a derrocada desse projeto, já decidido antes no campo da economia.

Mesmo que, em um futuro próximo, o PT retorne ao poder por meio das eleições, não terá condições de reproduzir o esquema lulista de conciliação de classes. O aprofundamento do atual padrão de reprodução capitalista, as incertezas da economia mundial e as transformações na própria relação entre as classes sociais de nossa formação social, pautadas hoje por um conservadorismo liberal, apontam para um cenário muito diferente das condições sociais que possibilitaram a ascensão do lulismo.

\section{REFERÊNCIAS}

BERRINGER, Tatiana. A burguesia brasileira e a política externa nos governos FHC e Lula. Curitiba: Appris, 2015.

BRASIL lidera ranking de assassinato de ambientalistas. Exame, 20 abr. 2015. Brasil. Disponível em: http://exame.abril.com.br/brasil/brasil-lidera-ranking-de-assassinato-deambientalistas/. Acesso em: 18 out. 2018.

DELGADO, Guilherme Costa. Do capital financeiro na agricultura à economia do agronegócio. Porto Alegre: UFRGS Editora, 2012.

DIEESE. Política de Desenvolvimento Produtivo: Nova Política Industrial do Governo. São Paulo: Nota Técnica Nº 67, maio de 2008.

FELICIANO, Carlos Alberto. A prática da violência no campo brasileiro no século XXI. Disponível em: http://www.reformaagrariaemdados.org.br/sites/default/files/A\%20pratica\%20da\%20violenci a\%20no\%20campo\%20do\%20seculo\%20XXI.pdf.

FERNANDES, Adriana; FROUFE, Célia. Dívida pública cresceu 105\% com Lula. Estadão. 02 fev. 2011. Economia \& Negócios. Disponível em:

https://economia.estadao.com.br/noticias/geral,divida-publica-cresceu-105-com-lulaimp-,674086. Acesso em: 20 nov. 2018.

FILGUEIRAS, Vitor Araújo et al. Saúde e segurança do trabalho na construção civil brasileira. Aracaju: J. Andrade, 2015.

FERREIRA, Carla; LUCE, Mathias (orgs.). Padrão de reprodução do capital. São Paulo: Boitempo, 2012. 
GOES, Fernanda Lira. Financiamento do BNDES para obras e serviços de empresas brasileiras no exterior. São Paulo: IPEA, 2016. Disponível em: http://www.ipea.gov.br/portal/images/stories/PDFs/TDs/td_2297.pdf.

HIRATUKA, Célio; SARTI, Fernando. Investimento direto e internacionalização de empresas brasileiras no período recente. São Paulo: IPEA, 2011.

LAPLANE, Mariano; COUTINHO, Luciano; HIRATUKA, Célio (org.).

Internacionalização e desenvolvimento da indústria no Brasil. São Paulo: Unesp, 2003.

LISBOA, Marijane Vieira. Balanço da política ambiental do governo Lula: grandes e duradouros impactos. In: PAULA, Marilene de (org.). "Nunca antes na história desse país"...? Um balanço das políticas do governo Lula. Rio de Janeiro: Fundação Heinrich Böll Stiftung, 2011.

LUCE, Mathias Seibel. O subimperialismo revisitado: a política de integração regional do governo Lula. Tese (Mestrado em Relações Internacionais) -Universidade Federal do Rio Grande do Sul, Porto Alegre, 2007.

LUCE, Mathias Seibel. Teoria Marxista da Dependência - Problemas e categorias, uma visão crítica. São Paulo: Expressão Popular, 2018.

MORENO, Camila. O Brasil made in China: para pensar as reconfigurações do capitalismo contemporâneo. São Paulo: Fundação Rosa Luxemburgo, 2015.

OLIVEIRA, Chico; BRAGA, Ruy ; RIZEK, Cibele (orgs.). Hegemonia às avessas. São Paulo: Boitempo, 2010.

PARA historiadora, eleição de Bolsonaro marca fim da Nova República. Entrevista cedida a Luciana Neves. Revista Fórum. 04 nov. 2018. Disponível em:

https://revistaforum.com.br/politica/para-historiadora-eleicao-de-bolsonaro-marca-fim-danova-republica/. Acesso em:

POCHMAN, Márcio. Estado brasileiro é ativo e criativo. Entrevista cedida a Patricia Fachin. Revista IHU. São Leopoldo, n. 322, p. 16, 22 mar. 2010.

RICCI, Rudá. Lulismo: da era dos movimentos sociais à ascensão da nova classe média brasileira. Rio de Janeiro: Contraponto, 2013.

SINGER, André. Os sentidos do lulismo. São Paulo: Companhia das Letras, 2012.

SINGER, André. O lulismo em crise. São Paulo: Companhia das Letras, 2018.

STÉDILE, João Pedro (org). A questão agrária no Brasil, Vol. 7: O debate na década de 2000. São Paulo: Expressão Popular, 2013.

ZIBECHI, Raúl. Brasil potência: entre a integração regional e um novo imperialismo. Rio de Janeiro: Consequência, 2012. 